Authors can make their articles Open Access by archiving their article at no charge via the Green route.

Authors who have published in a subscription journal can do this by depositing the version of the article accepted for publication (version 2 ) in their own institution's repository.

Os autores podem disponibilizar seus artigos em acesso aberto, arquivando, sem custo em um Repositório Institucional.

Os autores que tiverem publicado em um periódico podem fazer isso pelo depósito da versão do artigo aceito para publicação (versão 2 ) no repositório da sua própria instituição. 


\title{
The impact of computer usage on scholarly communication among social scientists
}

\author{
Sely Costa and Jack Meadows \\ Loughborough University, UK Received 17 December 1999
}

\begin{abstract}
.
An examination has been made of the effects of using information technology on the communication of research by social scientists in Brazil. Two disciplines were studied economics and sociology - via both interviews and a questionnaire survey. A small sample of UK social scientists was also interviewed. The results indicate that major changes in communication habits are occurring. These are already well advanced for informal communication and are beginning to appear for formal communication. Differences have been found between economists and sociologists, with the former more active in their use of electronic facilities. Along with such discipline-related differences, the developments also appear to be influenced, in part, by pressures from the research community and from the institutional environment. One significant impact of information technology seems to be an increasing democratisation of the international research community.
\end{abstract}

\section{Introduction}

The impact of computer usage on scholarly communication has been studied increasingly in recent years. Attention has tended to concentrate on the sciences, with fewer studies of the social sciences, and most of this work has been concerned with specific disciplinary groups. It is already clear that differences exist between different disciplines (see, for example, [9]). The purpose of the present investigation has been to characterise the changing role of computer-based communication in the social sciences via a study of two of its disciplines. One - sociology - was selected because it provides the central core of the social sciences. The other - economics - is at the 'harder' (more quantitative) end of the social sciences. It therefore has something in common with the sciences and it also provides a contrast with a number of the fields in sociology. In geographical terms, the work reported here examined social scientists in Brazil (with a supplementary investigation in the UK), since work on computer-mediated communication has hitherto concentrated almost entirely on 
developed countries. As most social science scholars work in higher education, the present study has been restricted to academic staff in universities.

Studies of communication are, of course, concerned with group interactions. The groups involved in this case are the scholarly communities in the relevant disciplines. The concept of 'community' has been a focus of sociological interest for many years, yet it has proved difficult to agree on what it covers. Indeed, it has been said that:

The concept of community has been the concern of sociologists for more than two hundred years, yet a satisfactory definition of it in sociological terms appears as remote as ever [1].

The basic feature of most discussions of 'community' is the need to establish the boundaries that separate members of the community from nonmembers. The items most frequently mentioned in this context relate to geographical space, social interaction and mutual bonds. Traditionally, sociologists have distinguished between two types of interaction: direct (face to face) and mediated. This distinction can be applied to traditional scholarly communities, e.g. by differentiating between interactions within a research group at an institution and its members' interactions with external personnel. Even so, the international nature of the scholarly community has often made it difficult to specify geographical boundaries. The introduction of computer-based interaction has greatly complicated the picture. Not only is communication via the World Wide Web theoretically unbounded in geographical terms, but the distinction between direct and mediated inter-action also becomes blurred. This raises the need to question whether the transition of a scholar community from its reliance on traditional forms of communication to a virtual (online) community involves a change in the scope or nature of that community. A major objective of the present investigation is to see whether indications of such a change can yet be distinguished.

For this purpose, it is necessary to examine the factors at work in the operations of a scholarly community. Tubbs [10] has suggested a conceptual model for the study of group interactions that invokes three categories of 
variable. The first relates to the characteristics of the individual members of the community (age, gender, attitudes, etc), while the second takes into account the nature of the group and the environment in which it operates. The final category of variable relates to the consequences of interaction, e.g. changes in interpersonal relationships or in information flows. In this model, the first two sets of variables affect each other. Their output, in turn, produces consequences for the variables relating to group interaction. These then feed back to affect both individual and group characteristics. We have adapted this model to suit the purposes of the present investigation. We have retained the first set of individual characteristics, but have expanded the second set of environmental characteristics. We see scholars and their communities as influenced both by pressures (social, economic, political) and by the resources available (infrastructure, services, sources). Since we are concerned with university staff, these pressures and resources can be further categorised into those internal to the individual's institution and those external to it. The introduction of information technology (IT) into the academic environment provides both new resources and new pressures.

Studies of social scientists typically show that they have information requirements which differ systematically from scientists in terms of the types of resource used. They are, for example, much more reliant on government documents, newspapers, working papers and reports [4]. Again, journals and books are both major sources of information for social scientists as for scientists, but books figure much more prominently in the requirements of social scientists. Though these overall similarities serve to distinguish the information needs of social scientists, there are also clear differences within the social sciences. For example, it has been found that the reliance on books is appreciably greater in sociology than in economics [6].

In looking for corresponding differences in the use of computer-mediated communication, it has to be remembered that scientists were provided with computers and access to networks well before these became widely available to social scientists. In consequence, it is difficult to draw comparisons from most surveys made earlier than the mid-1990s. Even the more recent surveys reflect an imbalance $[2,6,9,11]$. They all indicate that scientists use computers and 
networks more - in terms both of numbers using and of frequency of use - than social scientists. The latter, in turn, employ them more than do scholars in the humanities. However, two points are apparent from these surveys. The first is that the differences between the groups continue to decrease. The second is that, if attention is concentrated specifically on the use of computer networks for communication, there is already little difference between the groups. For example, academics in all subjects are now using e-mail to much the same extent.

In looking for differences stemming from the transition to computer-based activities, the obvious focus is on changes in communication. However, these changes can affect other factors of importance to individual scholars and their communities. Two such factors are of basic importance and will be explored further here: productivity and creativity. An early study [8] found that respondents perceived computerisation as improving their writing efficiency and research productivity. More recently, two studies $[2,5]$ have found a positive association between the use of the Internet by scholars and their productivity. This productivity increase may be related in part to the increasing coauthorship of papers and coordination of research via the Web [7]. So far as creativity is concerned, Morton and Price [8] found that social scientists involved in quantitative work were more likely than other respondents to credit computers with improving their research creativity. Little work seems, as yet, to have been reported on the effect of networking on creativity. According to one small-scale ad hoc study [3], some two-thirds of the respondents considered that being connected to the Internet made them more creative.

\section{Questionnaire survey}

In view of this interest in productivity and creativity, it seemed appropriate to concentrate on research-active social scientists. In Brazil, this meant essentially staff at those higher education institutions which provide postgraduate programmes. The Higher Education Personnel Training Coordination Department (CAPES) of the Ministry of Education in Brazil has the responsibility for postgraduate programmes. It put together a special file for the present investigation, listing the names of all the academics involved in 
Brazilian postgraduate programmes in economics and sociology. After eliminating overlaps between programmes, this provided a sample of 760 academics (with approximately equal numbers of economists and sociologists) spread over a total of 28 higher education institutions (predominantly federal universities).

As a first stage, questionnaires were dispatched to this sample, with the intention of obtaining a semiquantitative overview of the situation. Unfortunately, staff at a number of the target universities went on strike immediately after the dispatch of the questionnaires. This clearly affected the return of the questionnaires. In view of this, the final response rate of $64.1 \%(67.4 \%$ economists; $60.6 \%$ sociologists) can be considered satisfactory.

The second stage involved a more qualitative, indepth investigation based on face-to-face interviews. A pilot study of eleven UK academics (seven economists; four sociologists) was implemented first. The intention here was both to test the interview structure for Brazil and to obtain information which, supplemented by the surveys reported in the literature, might provide a basis for comparing the situation in Brazil with that in the UK. To help in deciding on the Brazilian interview sample, CAPES provided another list containing the annual publications record of each economist and sociologist. It was decided to select staff for interview from eight postgraduate programmes in each subject area. Of these, seven were chosen because they included scholars with the highest productivity in their fields. The remaining one was selected for comparison purposes from programmes with less productive staff. An attempt was also made to obtain a reasonable gender balance among the interviewees. Altogether, 36 interviews were carried out (sixteen economists; 20 sociologists).

The first part of the questionnaire covered demographic characteristics to determine whether there were any major differences between the samples of economists and sociologists. The first significant difference related to gender. Only $16.0 \%$ of the economists were female, as compared with $44.6 \%$ of the sociologists. There was also a difference in intellectual mobility (defined as the number of years a respondent had worked in the same specialism). Although most respondents from both groups had worked in the same specialism for 
more than ten years, economists were significantly more likely than sociologists to have changed their specialism within that period. For physical mobility (defined as the number of years working in the same institution), there was no significant difference between the two groups, with a considerable majority of both groups having worked in the same institution for more than ten years. Nearly half of the respondents in both subjects had obtained their postgraduate qualification abroad. There seemed to be a preference for US qualifications among the economists and for European qualifications among the sociologists.

Over $90 \%$ of the respondents made some use of computers, with over $40 \%$ of the economists and over $50 \%$ of the sociologists having more than five years' computer experience. Many used computers, typically stand-alone, at home. Networked computers were more readily available at work, but economists were better catered for in this respect than sociologists. Thus, $77.7 \%$ of the economists had networked computers on their desks at work, as compared with $59.0 \%$ of the sociologists. Altogether, some $90 \%$ of respondents had some kind of computer they could use. The great majority accessed these either weekly or more frequently.

Though easy access to networked computers was therefore not universally available, overall usage of online information services was significant. For example, though $99 \%$ of the respondents had read printed journals, as many as $68 \%$ had consulted electronic journals. The more meaningful figures are, however, those for frequent usage (weekly or more often). For this, consultation of printed journals falls by a relatively small amount to $85.6 \%$, whereas for electronic journals it falls to $23.9 \%$. In a similar way, fulltext databases have been searched at some time by $66.6 \%$ of the respondents, but frequently by only $14.6 \%$. The corresponding figures for searching numerical databases are $55.1 \%$ and $11.9 \%$.

The overall impression from the responses is that though traditional information sources and services are still dominant, their electronic equivalents are catching up rapidly. For example, $83.3 \%$ of respondents made use of printed abstracts (18.7\% frequently), while $72 \%$ used online bibliographic databases $(16.4 \%$ frequently). Similarly, $85.3 \%$ searched the library card 
catalogues (25.7\% frequently), compared with $70.3 \%$ who searched the library online public access catalogues (19.8\% frequently). There were significant differences in this between economists and sociologists, with the former making greater use of a range of electronic facilities (e.g. Web sites, bulletin boards) and the latter making more use of traditional facilities (e.g. card catalogues, printed abstracts). There was also some indication (mainly at the $5 \%$ significance level) that male respondents tended to use electronic sources and services more than female respondents.

A series of questions was asked about respondents' expectations regarding the impact of networked computers on their own communication practices. Table 1 records their views of eight possible developments. The two questions where their replies indicated most uncertainty were those concerning publication in electronic journals and the likelihood of improvements in creativity. With the exception of this latter, more than half the respondents responded affirmatively to each question, though sociologists tended overall to be somewhat more pessimistic than economists.

Respondents were next asked questions about the expected impact of networked computers on their scholarly community. Table 2 indicates that here, too, over half the respondents to each question believed that major changes would occur. A further question was posed about future governmental and institutional policies, i.e. whether these might be expected to aid the development of scholarly community activities. The answers showed a difference of opinion between the economists and the sociologists, with the former much more likely (significant at the $1 \%$ level) to believe that they would. Similarly, more economists than sociologists thought that networked computers would make collaborative work easier (also significant at the 1\% level). Table 2 suggests that the overall trend is again for economists to be rather more positive towards change than the sociologists. 
Table 1

Respondents' own expectations of networked computers

\begin{tabular}{llllllc}
\hline Expectation & \multicolumn{2}{l}{ Agree } & \multicolumn{3}{c}{ Not sure } & \multicolumn{2}{c}{ Disagree } \\
\cline { 2 - 7 } & $\begin{array}{l}\text { Economists } \\
(\%)\end{array}$ & $\begin{array}{l}\text { Sociologists } \\
(\%)\end{array}$ & $\begin{array}{l}\text { Economists } \\
(\%)\end{array}$ & $\begin{array}{l}\text { Sociologists } \\
(\%)\end{array}$ & $\begin{array}{l}\text { Economists } \\
(\%)\end{array}$ & $\begin{array}{l}\text { Sociologists } \\
(\%)\end{array}$ \\
\hline Increase informal communication & 86.9 & 77.8 & 10.0 & 15.6 & 3.1 & 6.6 \\
Increase publications & 81.9 & 76.0 & 15.1 & 16.0 & 3.0 & 8.0 \\
Improve quality of work & 95.8 & 89.3 & 2.3 & 7.1 & 1.9 & 3.6 \\
Publish electronic journal articles & 55.0 & 57.8 & 40.0 & 36.9 & 5.0 & 5.3 \\
Widen the scholarly community & 86.1 & 85.3 & 11.6 & 11.2 & 2.3 & 3.5 \\
$\begin{array}{l}\text { Produce more work in less time } \\
\text { Improve creativity }\end{array}$ & 90.3 & 84.0 & 6.6 & 10.7 & 3.1 & 5.3 \\
$\begin{array}{l}\text { Make it easier to find relevant } \\
\quad \text { information }\end{array}$ & 50.2 & 45.5 & 32.7 & 28.4 & 17.1 & 26.1 \\
\hline
\end{tabular}

Table 2

Respondents' expectations regarding their scholarly community

\begin{tabular}{|c|c|c|c|c|c|c|}
\hline \multirow[t]{2}{*}{ Expectation } & \multicolumn{2}{|l|}{ Agree } & \multicolumn{2}{|l|}{ Not sure } & \multicolumn{2}{|l|}{ Disagree } \\
\hline & $\begin{array}{l}\text { Economists } \\
(\%)\end{array}$ & $\begin{array}{l}\text { Sociologists } \\
(\%)\end{array}$ & $\begin{array}{l}\text { Economists } \\
(\%)\end{array}$ & $\begin{array}{l}\text { Sociologists } \\
(\%)\end{array}$ & $\begin{array}{l}\text { Economists } \\
(\%)\end{array}$ & $\begin{array}{l}\text { Sociologists } \\
(\%)\end{array}$ \\
\hline Make collaborative work easier & 83.0 & 68.3 & 14.7 & 26.8 & 2.3 & 4.9 \\
\hline Lead to new scholarly communities & 60.6 & 56.1 & 36.7 & 39.9 & 2.7 & 4.0 \\
\hline $\begin{array}{l}\text { Reduce the time spent on peer } \\
\text { review }\end{array}$ & 59.1 & 57.0 & 39.8 & 37.6 & 1.1 & 5.4 \\
\hline $\begin{array}{l}\text { Increase the number of projects } \\
\text { concerned with IT }\end{array}$ & 55.6 & 60.3 & 43.2 & 34.4 & 1.2 & 5.3 \\
\hline
\end{tabular}

\section{Interview survey}

The questions asked at the interviews in Brazil were primarily intended to supplement and extend the questionnaire data contained in Tables 1 and 2: it was found that the interview responses accorded well with those obtained from the questionnaire survey. The first question concerned informal communication, including particularly e-mail. Most interviewees believed that informal communication via electronic networks was now both expected by the community and required by their work. As one economist commented:

I was forced to use e-mail because I work with colleagues who are in other cities. So, I communicate with them about research issues in order to write papers in collaboration. I have been using it for administrative issues, to organise events, meetings, etc, as well. I also communicate with students. I have, for example, a supervisee who is in Princeton, in the USA, and e-mail has been fundamental.

A number of the respondents noted that searching for information via the Internet was also coming to be expected. Some pointed out that networking 
from their institution was rather poor, so they communicated from home, using private providers despite the cost.

There was greater disagreement over community expectations regarding the use of formal electronic publications (mainly electronic journals). Interviewees were split evenly on the question of whether there was community pressure to access such publications. Economists were more likely than sociologists to see use of electronic publications as already expected of them, but both groups saw a trend in this direction. However, few felt under pressure, as yet, to publish in a purely electronic format. An economist remarked:

I feel that there are expectations in relation to electronic journals, though they are less than in relation to informal communication. It has become very common to use electronic media to know about journal contents and see abstracts, as well as to obtain entire articles in electronic format.

The next question asked whether respondents had noticed any changes in their scholarly community as a consequence of the availability of electronic communication. An overwhelming majority said that they had. Two points were particularly remarked. The first concerned increased interactivity within the community. As a sociologist explained:

I think there certainly is a change in the scholarly community, mainly in relation to interactivity. Our relationship with international environmental sociology, particularly American environmental sociology, is only possible in a recurrent way due to the use of e-mail. At the same time, the penetration of this international debate into Brazil only occurred because we communicate via the Internet.

The second point concerned community boundaries: it was widely accepted that the use of IT was helping to extend participation in scholarly communities. An economist can be quoted here:

The scholarly community has become much broader because access has become more democratic. Information circulation has become much easier, especially for international information. The Internet is the great change factor. It 
has modified the way the community interacts without doubt, and has also reduced the geographical distances.

The position with regard to financial pressures is more complex. Though Brazilian universities have not always had adequate internal funding for acquisition of IT, considerable amounts of funding for equipment have been made available by external bodies. Even where institutional inadequacies have had to be offset by individual academics buying their own equipment for use at home, some have been helped in this by subsidised loans, either from their own institutions or from the funding agencies. The overall result is that, to the extent that any pressure was felt, it derived mainly from the need to make full use of the equipment, especially where this had been provided by external funding agencies. In terms of policy factors affecting the funding, most respondents believed that the universities provided the essential technological infrastructure so far as their finances allowed them. To some extent, this was also thought to be true of Brazilian government policy, especially in the decision to make the Internet available to all academic researchers as soon as possible. However, there was some criticism of the retarding effects exerted by government taxation of imported computers.

The next part of the interview explored the transition to electronic communication; more especially, whether such communication should be seen as a complement to, or a substitute for, traditional printed publications. Economists were almost equally divided on this question, whereas most sociologists saw electronic communication as complementary. In part, this was because the two groups had rather differing types of publication in mind, with sociologists more inclined to think in terms of books. There was a general feeling that electronic journals would gradually be accepted, though it might take some time:

We feel a bit suspicious about the credibility of a purely electronic journal, but I suppose that, in the future, it will have as much credibility as a printed one. It will take some time for us to make sure they are undergoing peer review, have a good institution supporting them, etc. 
As compared with journals, there was considerable attachment to the traditional book. In addition, many respondents objected to reading extended pieces of text from a computer screen. However, some respondents recognised that future developments depended, in part, on the nature of the scholarly community involved:

There are themes that are relevant, but do not justify the production scale that the printed media need. You sometimes have communities that deal with themes that have 50 or 100 persons involved. Electronic media, without doubt, can be the solution to journal publication on themes that are relevant, but do not justify large-scale production. They could help to disseminate this sort of knowledge within smaller communities.

Respondents were asked whether their use of IT had had any impact on their own productivity - either by increasing the number of their publications or by making it easier to put them together. The great majority believed that both effects were at work, though a number also warned that use of computers could not compensate for weak research content. A typical comment was:

I think it helps to increase my work by the extent to which I have more access, more information: it gives me more speed, so I can do things faster. It both facilitates doing things faster and also improves the quality, because I can do a more efficient bibliographic search, come closer to the social science frontier. The access by Third World researchers to the social science frontier is more democratic now.

The point made in the latter part of this comment was linked by several respondents to the increased possibility of collaborative work using electronic networks. For them, collaboration had been enhanced both nationally and internationally (especially with North America and Western Europe, the two main providers of foreign postgraduate qualifications). For example:

I have carried out two research projects with two different groups. The first one with a Canadian group, in which we worked via the Internet, and now I am carrying out research with a German group. We exchange all data via the Internet. 
Most respondents agreed that the ready availability of IT had increased their motivation to communicate with other members of their scholarly community both nationally and internationally. Respondents were finally asked whether they felt that their use of IT had had any impact on their creativity. The majority thought there had been no such influence, though economists were appreciably more likely than sociologist to discern an effect. Those who saw a link typically cited two factors: the greater range of information available, which stimulated new ideas, and the freeing of more of their time, which gave greater opportunities for reflection.

\section{Discussion}

In terms of demographic variables, the questionnaire survey found few significant differences in the sample. It is true that female respondents seemed slightly less positive towards IT-based activities than male respondents, but much of this could be explained by the fact that many more females were sociologists than economists. For there was a clear-cut difference between economists and sociologists. The former were significantly more likely than the latter to make use of electronic facilities. In part, this appears to be a genuine difference; both the questionnaire survey and the interviews suggest that the economists have a more positive attitude than sociologists to present and future use of IT. In part, the difference between the two groups reflects differences in their funding, since economists were significantly better provided with easy access to networked computers.

Responses regarding the impact of IT on productivity confirmed the existence of a positive link. The responses regarding creativity were more diverse, but some interviewees certainly believed a link also existed there. In this case, unlike productivity, where both groups were in agreement, there was some indication of a more positive response from economists; so the perceived impact of IT on creativity may perhaps be influenced by the discipline.

Our original model suggested that individual attitudes should interact with environmental changes. This interaction should lead to changes in the community, which then feed back again to influence the individuals and their 
environments. This model seems to reflect a number of the developments examined in the questionnaire survey and the interviews. For example, online research collaboration was examined as part of the study of productivity. It is apparent that the individual motivation to communicate with fellow researchers has received a major impetus from the growth of an IT environment. This interaction has led to a broadening of the research community, as perceived by individual researchers. In consequence, the research community has become increasingly internationalised. In terms of feedback, this has increased the dependence of individuals on electronic communication, which means, in turn, that they are increasingly demanding an improved IT environment.

As suggested earlier, these interactions can be visualised as being subject to various pressures. On the one hand, there are clearly communal pressures on researchers to use electronic means of information handling and communication. The most obvious such pressure is the expectation that e-mail communication will be commonly used. It is possible to see a hierarchy of expectation at present. For example, some respondents believe there is a community expectation that they will access electronic publications regularly. The pressure for this is seen as being less strong than that demanding their employment of e-mail. There is even less communal expectation that researchers will actually publish in a purely electronic form (as in some electronic journals). However, many respondents see the situation as evolving rapidly with time and so expect communal pressures requiring the use of electronic facilities to grow across the board. On the other hand, there are institutional pressures affecting the research environment. For example, there are regional variations in the provision of a satisfactory electronic environment. Those who have good facilities correspondingly believe there is an institutional expectation that they will make full use of them. More interestingly, many respondents have tried to overcome deficiencies in provision by purchasing their own equipment. This appears to reflect both the perceived value of IT for research and the expectations of their community.

As this implies, the growing importance of IT - more especially, of the Internet - is introducing changes into the social science community. The key factor is greater interactivity. This means not only increased information 
exchange with known contacts, but also the making of new contacts. Several respondents reported that they now had more comprehensive contacts with fellow researchers. Indeed, electronic communication was, in some cases, widening the boundaries of whom they saw as members of their community. Electronic facilities were also seen as extending access to information and so helping to overcome local deficiencies in traditional information sources. The extent to which electronic access to information was seen as important depended on the nature of the research. An interest in hard data and relatively brief amounts of text led to a higher valuation of electronic facilities.

A comparison of these Brazilian results with information gathered from UK interviews and from data in the literature suggests very little difference between the reactions of Brazilian social scientists and of those in developed countries. This is true not only as regards the way in which they actually use electronic facilities, but also in their assessment of the impact such facilities are having. Thus, their perceptions of the impact of IT both on the research community and on the activities of individual researchers are very similar. Provision of academic networking is a matter for central government in Brazil, whereas it has been primarily guided by the universities in the UK. The overall result is that Brazilian social scientists are appreciably more concerned about IT policy questions than their counterparts in the UK.

That differences between a developing country and developed countries can be so small underlines a point made by a number of respondents. Electronic communication is having the effect of democratising the social science research community. This means more than simply that it provides a less uneven playing field in terms of access to information. It means further that researchers in the social sciences from developing and developed countries can interact with each other on the same footing. The result is that the social science research community seems to be moving towards a greater international homogeneity. 


\section{References}

[1] C. Bell and H. Newby, Community Studies: An Introduction to the Sociology of the Local Community (Allen and Unwin, London, 1971).

[2] J. Cohen, Computer mediated communication and publication productivity among faculty, Internet Research: Electronic Networking Applications and Policy 6 (1996) 41-63.

[3] W. Crawford, Creativity and Connectedness: Results (1992). URL: http://listserv.uh.edu/cgi-bin/wa?A2=ind 9210b\&L=pacs-1\&F=\&S=SP=4292

[4] C.C. Gould and M.J. Handler, Information Needs in the Social Sciences: An Assessment (Research Libraries Group, Mountain View, CA, 1989).

[5] N. Kaminer and Y.M. Braunstein, Bibliometric analysis of the impact of Internet use on scholarly productivity, Journal of the American Society for Information Science 49 (1998) 720-730.

[6] S.L. Lazinger, J. Bar-llan and B.C. Peritz, Internet use by faculty members in various disciplines: a comparative case study, Journal of the American Society for Information Science 48 (1997) 508-518.

[7] A. Lubanski and L. Matthew, Socio-economic impact of the Internet in the academic research environment. In: IRISS '98 Conference Proceedings (1998). URL: http://www.sosig.ac.uk/iriss/papers/paper18.htm

[8] H.C. Norton and A.J. Price, The ACLS Survey of Scholars: Final Report of Views on Publications, Computers and Libraries (University Press of America, Lanham, Washington, DC, 1989).

[9] D. Schauder, Electronic publishing of professional articles: attitudes of academics and implications for the scholarly communication industry, Journal of the American Society for Information Science 45 (1994) 73-100.

[10] S.L. Tubbs, A Systems Approach to Small Group Interaction (AddisonWesley, Reading, MA, 1978). 
[11] H.J. Voorbij, Searching scientific information on the Internet: a Dutch academic user survey, Journal of the American Society for Information Science 50 (1999) 598-615. 